\title{
QUALIDADE MICROBIOLÓGICA E FÍSICO-QUÍMICA DA ÁGUA DOS AÇUDES URBANOS UTILIZADOS NA DESSEDENTAÇÃO ANIMAL EM SOBRAL, CEARÁ
}

\author{
Yara Arruda MAGALHÃES ${ }^{1}$ \\ Ana Sancha Malveira BATISTA ${ }^{1}$ \\ Raquel Oliveira dos Santos FONTENELLE ${ }^{2}$ \\ Murilo Sérgio da Silva JULIÃO ${ }^{3}$ \\ Phâmela Marjoire Gomes LOIOLOA ${ }^{1}$ \\ Rômulo Melo MESQUITA ${ }^{1}$ \\ Francisca Lidiane Linhares de AGUIAR $^{4}$ \\ Andrelane Ribeiro OLIVEIRA ${ }^{3}$
}

\author{
${ }^{1}$ Universidade Estadual Vale do Acaraú, Centro de Ciências Agrárias e Biológicas, Departamento de Zootecnia, Sobral, \\ Ceará, Brasil. \\ ${ }^{2}$ Universidade Estadual Vale do Acaraú, Centro de Ciências Agrárias e Biológicas, Departamento de Ciências \\ Biológicas, Sobral, Ceará, Brasil. \\ ${ }^{3}$ Universidade Estadual Vale do Acaraú, Centro de Ciências Exatas e Tecnologia, Departamento de Química, Sobral, \\ Ceará, Brasil. \\ ${ }^{4}$ Universidade Estadual do Ceará, Centro de Ciências e Tecnologia, Departamento de Pós-graduação em Recursos \\ Naturais, Fortaleza, Ceará, Brasil. \\ *Endereço para correspondência: yara.zootecnia@gmail.com
}

Recebido em: 28/05/2014 - Aprovado em: 17/09/2014 - Disponibilizado em: 15/12/2014

\begin{abstract}
RESUMO: Objetivou-se avaliar a qualidade microbiológica e físico-química da água dos açudes urbanos de Sobral, Ceará, a fim de conhecer a qualidade da água ingerida pelos animais criados nas redondezas desses açudes. Foram coletadas amostras de água de ambos os açudes realizando as seguintes determinações: contagem do número mais provável de coliformes totais e termotolerantes, contagem de aeróbios mesófilos e identificação de espécies bacterianas isoladas das amostras, $\mathrm{pH}$, alcalinidade, sólidos totais dissolvidos e temperatura. Observou-se a presença de coliformes totais e termotolerantes, sendo verificada a presença de Escherichia coli e Yersínia enterocolítica, que mesmo sendo indicativos de contaminação fecal não tornam a água imprópria para consumo animal, pois o número mais provável desses micro-organismos e contagem de aeróbios mesófilos encontram-se dentro do preconizado pela legislação brasileira. Os valores de $\mathrm{pH}$ de ambos os açudes encontram-se acima dos valores aceitos pela legislação, diferentemente dos valores da quantidade de sólidos totais dissolvidos, que estão bem abaixo do limite máximo estabelecido. De acordo com os critérios da legislação brasileira de avaliação de qualidade da água, ambos os açudes da área urbana de Sobral podem ser utilizados para dessedentação animal, sob a condição de receber algum tratamento simplificado tal como desinfecção por radiação.
\end{abstract}

Palavras-chave: coliformes, contaminação, micro-organismos, recursos hídricos.

\section{MICROBIOLOGICAL QUALITY AND PHYSICAL-CHEMICAL OF WATER FROM THE URBAN RESERVOIRS USED IN WATERING ANIMAL IN SOBRAL, CEARÁ}

\begin{abstract}
Was to evaluate the microbiological quality and physico-chemical of water from the reservoirs city of Sobral, Ceará, in order to know the quality of the water consumed by animals reared in the vicinity of these dams. Water samples were collected from both reservoirs performing the following determinations: counting the most probable number of total and fecal coliforms, aerobic mesophilic count and identification of bacterial species isolated from the samples, $\mathrm{pH}$, alkalinity, total dissolved solids and temperature. We observed the presence of total and fecal coliforms, and verified the presence of Escherichia coli and Yersinia enterocolitica, even being indicative of fecal contamination not make the water unfit for animal consumption, as the most probable number of these micro-organisms and counting aerobic mesophilic are within the recommended by the Brazilian legislation. The values $\mathrm{pH}$ of both reservoirs are above the values accepted by the law, unlike the values of the amount of total dissolved solids, which are well below the threshold set. According to the Brazilian legislation criteria for evaluating water quality, both reservoirs in urban from Sobral can be used for watering animals, under the condition of receiving a simplified treatment as radiation disinfection.
\end{abstract}

Keywords: coliforms, contamination, microorganisms, water resources. 


\section{INTRODUÇÃO}

A água é essencial para a sobrevivência de todo ser vivo, além das funções fisiológicas que exerce no organismo animal, atua como solvente universal dispersando diversas substâncias. Vários são os fatores que levam os animais a consumirem água, mas a água ingerida pode interferir de forma negativa quando não for de boa qualidade, podendo acarretar problemas de saúde.

Geralmente as preocupações com a qualidade da água são voltadas somente para aquelas que são destinadas ao consumo humano. Entretanto, as preocupações com a qualidade hídrica geralmente não inclui aquela utilizada para dessedentação animal, negligenciando a saúde dos mesmos. Segundo Iturrino et al.(2010) dentre as diversas formas de veiculação de patógenos para animais, destaca-se a contaminação das rações bem como a água de dessedentação, assim, acarretando diminuição na eficiência alimentar e problemas de ordem sanitária, que culminam no desenvolvimento de doenças e consideráveis prejuízos a esse sistema de produção.

No gerenciamento dos reservatórios de água é essencial o monitoramento dos parâmetros físicos, químicos e biológicos da qualidade de água que, por sua vez, permitam inferir sobre possíveis fontes de poluentes que possam prejudicar o uso a que estes reservatórios são destinados (Lima e Garcia, 2008).

As formas mais comuns de contaminações devem-se à presença de microorganismos, poluentes despejados no meio aquático ou no ambiente de forma que venha a prejudicar os recursos hídricos. A poluição das águas pode aparecer de várias formas, sendo mais preocupantes aquelas que não podem ser detectadas pelos órgãos do sentido, sendo assim, na caracterização da qualidade da água, utilizam-se alguns parâmetros que representam suas características biológicas e físico-químicas, tais como alcalinidade, $\mathrm{pH}$, sólidos totais dissolvidos e temperatura, que apresentam as impurezas e são os indicadores da qualidade da água (Pinto et al., 2009)

O município de Sobral, localizado no estado do Ceará, dispõe de dois açudes na zona urbana, ambos têm a água utilizada para irrigação de capineiras e hortaliças, recreações humanas e dessedentação de animais domésticos pertencentes aos pequenos produtores e criadores das redondezas.

Diante da carência de estudos relacionados a qualidade da água ingerida pelos animais em açudes e sendo este um ponto significativo na saúde e desempenho do animal, objetivou-se avaliar a qualidade da água dos açudes urbanos de Sobral.

\section{MATERIAL E MÉTODOS}

Foram coletadas amostras de água de um ponto aleatório de cada açude urbano do 
município de Sobral, Ceará, durante o mês de agosto de 2012. A coleta ocorreu em frascos de $500 \mathrm{~mL}$ esterilizados, mantidas sob refrigeração e conduzidas no mesmo dia aos laboratórios de Microbiologia e Química Analítica da Universidade Estadual Vale do Acaraú, onde foram realizadas as análises microbiológicas: contagem de coliformes totais (CT), coliformes termotolerantes (CTT) e identificação dos micro-organismos isolados. Também foram realizadas determinações físico-químicas como temperatura, $\mathrm{pH}$, alcalinidade e sólidos totais dissolvidos.

A determinação do número mais provável (NMP) de CT e CTT foi realizada pelo método da fermentação em tubos múltiplos, conforme APHA (1992). Foram utilizadas três diluições das amostras com repetições de cinco tubos para cada diluição. $\mathrm{Na}$ primeira série de tubos foram inoculados $10,0 \mathrm{~mL}$ da amostra em 10,0 $\mathrm{mL}$ de caldo lactosado em concentração dupla, nas séries seguintes foram inoculados $1000 \mu \mathrm{L}$ e $100 \mu \mathrm{L}$ da amostra em caldo lactosado simples. Os tubos foram incubados em estufa a $35^{\circ} \mathrm{C}$ por 48h. Para enumeração de CT foram retiradas alíquotas dos tubos positivos de lactosado e inoculados em Caldo Bile Verde Brilhante e incubados em estufa a $36^{\circ} \mathrm{C}$ por $48 \mathrm{~h}$. Foram inoculadas alíquotas dos tubos positivos de lactosado, com auxílio de uma alça de cromo níquel, em caldo Escherichia coli (EC) para quantificação de CTT. Os tubos inoculados de EC foram incubados em banho-maria a $45^{\circ} \mathrm{C}$ por $48 \mathrm{~h}$. Além da contagem de coliformes procedeu-se com testes tradicionais para a confirmação da presença de Escherichia coli nas amostras. Foram retiradas alíquotas dos tubos positivos de EC e semeados com alça de níquel-cromo em placas contendo meio MacConkey e incubados em estufa a $36^{\circ} \mathrm{C}$ por 24h. As colônias com características positivas para E. coli, com coloração rósea com halo de precipitação ou não, foram isoladas e identificados através do teste do ImVic (Indol, Vermelho de Metila, Voges-Proskauer e Citrato), segundo Koneman et al. (1993).

Procedeu-se também a contagem padrão em placas, através da técnica "pour plate", para determinação de microorganismos aeróbios mesófilos, sendo utilizadas três diluições das amostras em solução salina a $0,85 \%$. Foram retirados 1000 $\mu \mathrm{L}$ de cada uma das diluições de 10-1, 10-2 e 10-3 das amostras e adicionados em placas de Petri esterilizadas. Logo após, foram adicionados 15,0 mL de Ágar Padrão de Contagem (PCA). Misturou-se o inóculo com o meio de cultura movimentando suavemente as placas numa superfície plana, em movimentos em forma de oito. Após a completa solidificação do meio de cultura nas placas, as mesmas foram incubadas em estufa a $35^{\circ} \mathrm{C}$ por 24 horas. Utilizou-se duas repetições para cada diluição.

$\mathrm{Na}$ determinação do $\mathrm{pH}$, foi utilizado um potenciômetro (pHmetro) acoplado a um eletrodo de vidro indicador de $\mathrm{pH}$, ambos da Metrohm®. Antes de realizar as medidas de 
$\mathrm{pH}$ nas amostras, o eletrodo de $\mathrm{pH}$ foi calibrado com soluções tampão de $\mathrm{pH}$ iguais a 4,00; 7,00 e 9,00. Com o eletrodo de pH já calibrado, foram executadas as medidas de $\mathrm{pH}$ em 100 mL de amostras de água contidas num béquer. $\mathrm{O}$ procedimento foi realizado em triplicata para todas as amostras.

As medidas de temperatura foram realizadas com o sensor de temperatura acoplado ao pHmetro. Estas medidas foram realizadas em triplicata para melhor obtenção dos resultados.

A determinação da quantidade de sólidos totais dissolvidos foi executada com a técnica de filtração a vácuo em cadinho de fundo poroso (vidro sinterizado). Inicialmente, os cadinhos de vidro sinterizado foram secados a $60^{\circ} \mathrm{C}$ em estufa por $2 \mathrm{~h}$ para retirada da umidade, após resfriamento à temperatura ambiente em dessecador, foram pesados em balança analítica. Foram passadas alíquotas de $100 \mathrm{~mL}$ das amostras para cadinhos acoplados a um sistema de filtração a vácuo. Em seguida, os cadinhos foram novamente levados a estufa a $60^{\circ} \mathrm{C}$ por $24 \mathrm{~h}$ para secagem e após este período, foram pesados em balança analítica. A quantidade de sólidos totais dissolvidos foi calculada a partir da diferença entre as massas pesadas dos cadinhos antes e após a filtração das amostras de água.

A determinação da alcalinidade e das espécies alcalinas predominantes na amostra (hidroxila, carbonato e/ou bicarbonato) foi realizada a partir da volumetria de neutralização utilizando-se uma solução padronizada de ácido sulfúrico 0,010 mol L-1 na presença dos indicadores fenolftaleína e metilorange.

Para amostras de água com $\mathrm{pH}>8,0$ foi realizado o seguinte procedimento: 50,0 $\mathrm{mL}$ da amostra de água foram colocados num erlenmeyer de $250 \mathrm{~mL}$ na presença de fenolftaleína e titulada até o desaparecimento da coloração rósea. Após a adição do indicador metilorange, a amostra foi titulada até o ponto de viragem do indicador, ou seja, a coloração muda para vermelho-alaranjado.

Para amostras de água com $\mathrm{pH}<8,0$, uma alíquota de 50,0 mL da amostra de água foi colocada num erlenmeyer de $250 \mathrm{~mL}$ na presença de metilorange e titulada até o ponto de viragem desse indicador. Todas as titulações foram realizadas em triplicata.

Os valores de alcalinidade foram calculados de acordo com a equação:

Alcalinidade total $(\mathrm{mg}$. L-1 $)=\underline{\text { Vm . f. } 1000}$ $\mathrm{Va}$

Onde: $\mathrm{Vm}=$ volume médio da amostra; $\mathrm{Va}=$ volume de amostra usado na titulação e $\mathrm{f}=$ fator de correção da solução de ácido sulfúrico.

\section{RESULTADOS E DISCUSSÃO}

Os açudes A e B apresentaram o número de coliformes totais iguais a 2,6 x 10 NMP/100mL e 1,6 x 103 NMP/100mL, respectivamente (Tabela 1). O Conselho Nacional do Meio Ambiente - CONAMA que regulamenta as normas de potabilidade das 
águas brasileiras, na Resolução de $\mathrm{N}^{\mathrm{o}} 357$ de 17 de março de 2005, não determina limites máximos de coliformes totais para dessedentação animal. Silva \& Gallo (2003) afirmaram que tais micro-organismos oferecem risco baixo ou indireto à saúde animal, embora cause surtos diarreicos e infecções urinárias aos mesmos.

Tabela 1. Número mais provável (NMP) de coliformes totais (CT), coliformes termotolerantes (CTT), contagem de micro-organismos aeróbios mesófilos e pesquisa de Escherichia coli nas águas dos açudes urbanos de Sobral-CE

\begin{tabular}{lcccc}
\hline Açude & $\begin{array}{c}\text { NMP de } \\
\text { CT/100mL }\end{array}$ & $\begin{array}{c}\text { NMP de } \\
\text { CTT/100Ml }\end{array}$ & Escherichia coli & $\begin{array}{c}\text { Micro-organismos } \\
\text { aeróbios mesófilos } \\
\text { (UFC/mL) }\end{array}$ \\
\hline A & $2,6 \times 10$ & 6,8 & + & $8,0 \times 103$ \\
$\mathrm{~B}$ & $>1,6 \times 103$ & $2,7 \times 102$ & + & $1,1 \times 103$ \\
\hline
\end{tabular}

A presença de coliformes totais em matrizes ambientais não indica necessariamente contaminação fecal, pois esse grupo inclui diversos gêneros e espécies de bactérias não entéricas (Conte, 2004). Segundo Zulpo et al.(2006) coliformes totais podem ser encontrados no solo e nos vegetais, possuindo a capacidade de se multiplicarem na água com relativa facilidade.

CONAMA (2005) designa coliformes termotolerantes como bactérias gramnegativas, em forma de bacilos, oxidase negativa, caracterizadas pela atividade da enzima $\beta$-galactosidase, com capacidade pra fermentar lactose, assim, tolerando no máximo 1000 coliformes termotolerantes por 100 mL em águas para dessedentação animal. Ambos os açudes apresentaram concentrações de bactérias do grupo coliformes.

Estas bactérias costumam estarem presentes em fezes humanas e de animais homeotérmicos, solos, plantas e meios aquáticos. $\mathrm{O}$ número de coliformes termotolerantes foi $6,8 \mathrm{NMP} / 100 \mathrm{~mL}$ no açude A e 2,7 x $102 \mathrm{NMP} / 100 \mathrm{~mL}$ no açude $\mathrm{B}$, indicando que as amostras estão dentro dos padrões aceitáveis para dessedentação animal.

Das vinte e duas cepas isoladas nos dois açudes, 57,14\% correspondem a espécies de Escherichia coli e 28,57\% de Yersínia enterocolítica. As E. coli são bactérias gramnegativas, anaeróbias facultativas, encontradas como componentes da microbiota entérica animal e humana, sendo algumas linhagens patogênicas para o homem e animais (Mittelstaedt \& Carvalho, 2006), possuindo fatores de virulência fatais, como o sorotipo 0157:H7 (Topp, 2003). Embora a $E$. coli não seja considerada persistente, uma vez que a mesma é lançada do trato digestivo através das fezes dos animais ao solo, essa bactéria pode permanecer viável por diversos meses (Topp, 2003) e, como pertence a microbiota do intestino humano e animal, é utilizada para indicar contaminação de origem fecal.

Yersinia enterocolitica é uma bactéria gram-negativa que causa infecções em 
diversas espécies de mamíferos. O agente, geralmente, provoca infecções restritas ao intestino e linfonodos mesentéricos, porém a infecção pode se tornar sistêmica ocasionando lesões em outros órgãos como fígado e baço (Sonne et al., 2012).

Nos últimos anos, houve um aumento considerável da incidência dessa enterobactéria nos seres humanos e alimentos. No Brasil, $Y$. enterocolitica foi isolada do ser humano; de cães e suínos, enfermos e sadios; da água e de alimentos, como carne, leite e derivados; e vegetais, principalmente, nos estados de São Paulo, Rio de Janeiro e Rio Grande do Sul (Teodoro et al., 2006). Segundo Mollaret (1995), os suínos são considerados os principais reservatórios dessa bactéria.

Infecções em animais por $Y$. enterocolitica apareceram logo após a descrição da infecção no homem. No período compreendido entre 1960 a 1965, criações de chinchilas em fazendas da Alemanha e Dinamarca foram dizimadas por um grande surto. Concomitantemente, na França, Suíça e Inglaterra ocorreram contaminações em coelhos. Posteriormente, dados epidemiológicos mostraram que a infecção ocorria em roedores, na maioria das vezes, na forma subclínica e em suínos e bovinos na forma clínica (Mollaret, 1995).

A contagem de micro-organismos aeróbios mesófilos apresentou 8,0 x 103 $\mathrm{UFC} / \mathrm{mL}$ no açude A e 1,1 x $103 \mathrm{UFC} / \mathrm{mL}$ no açude B. A resolução do CONAMA (2005) também não estipula contagem máxima permitida de mesófilos em águas para consumo animal, entretanto sua presença em ambientes com temperaturas entre $20^{\circ} \mathrm{C}$ e $45^{\circ} \mathrm{C}$ favorece o crescimento bacteriano deste grupo. Considerando que ambos os açudes encontraram-se em temperatura de $25^{\circ} \mathrm{C}$ (Tabela 2), esses mesófilos estão em temperatura ótima de crescimento.

Tabela 2. Valores obtidos para os parâmetros físico-químicos analisados nas amostras

\begin{tabular}{lcccc}
\hline Açude & $\mathbf{p H}$ & Alcalinidade $(\mathbf{m g} / \mathbf{L})$ & $\begin{array}{c}\text { Sólidos totais dissolvidos } \\
(\mathbf{m g} / \mathbf{L})\end{array}$ & Temperatura $\left({ }^{\circ} \mathbf{C}\right)$ \\
\hline $\mathrm{A}$ & 9,38 & $90,24 \mathrm{mg} / \mathrm{L}$ & $7,00 \mathrm{mg} / \mathrm{L}$ & 25 \\
$\mathrm{~B}$ & 9,30 & $65,28 \mathrm{mg} / \mathrm{L}$ & $249 \mathrm{mg} / \mathrm{L}$ & 25 \\
\hline
\end{tabular}

O pH é uma medida do equilíbrio entre cargas de hidroxilas ( $\mathrm{OH}-)$ e íons de hidrogênio $\left(\mathrm{H}_{+}\right)$, sendo utilizada para mensurar o grau de acidez ou de alcalinidade de uma amostra (Hermes \& Silva, 2004). É um parâmetro que deve ser sempre avaliado, pois pode interferir no processo de coagulação-precipitação química durante o tratamento da água, na corrosão de tubulações e equipamentos, no crescimento microbiano dos sistemas biológicos de tratamento, na toxidez de certos compostos e nos constituintes da alcalinidade e acidez da água (Lima \& Garcia, 2008).

$\mathrm{O}$ pH dos açudes A e B, apresentaram, respectivamente, os valores 9,38 e 9,30, com margem de erro de $\pm 0,02$ (Tabela 2). O 
CONAMA (2005) estabelece valores de $\mathrm{pH}$ para dessedentação animal entre 6,0 e 9,0, sendo ainda exigido um tratamento simplificado desta água. Assim, os dois açudes em questão, encontram-se fora dos padrões para dessedentação animal em relação ao parâmetro de pH. Lima \& Garcia (2008) ao avaliarem a qualidade da água de açude e barragem, atribuíram elevados valores de $\mathrm{pH}$ à menor quantidade de água em períodos de estiagem.

A alcalinidade da água é representada pela presença dos íons hidroxila ( $\mathrm{OH}-)$, carbonato $\left(\mathrm{CO}_{32}-\right)$ e bicarbonato ( $\left.\mathrm{HCO}_{3}-\right)$. A importância do conhecimento das concentrações destes íons permite a definição de dosagens de agentes floculantes e fornece informações sobre as características corrosivas ou incrustantes da água analisada (Silveira; 2007). Apesar da importância desse parâmetro, a legislação brasileira não estabelece limite permitido para este parâmetro. Garcia \& Barreto (2010) ao caracterizarem a qualidade da água de um açude também mediram altos valores de alcalinidade e comprovaram que este parâmetro é maior no período seco do que chuvoso, que valores elevados da alcalinidade estão associados ao processo de decomposição da matéria orgânica e à alta taxa respiratória dos micro-organismos com consequente liberação e dissolução do gás carbônico na água.

Sólidos totais dissolvidos (STD) é a medida da concentração de todos os íons e sais resultantes da combinação de cátions e ânions que se encontram dissolvidos na água $\mathrm{e}$ materiais em suspensão, portanto, correspondem à fração dos solutos suspensos que passam por filtros com poros de 2,0 mm. Medidas de sólidos totais são importantes e devem ser realizadas onde ocorrem áreas de descargas industriais, áreas de irrigação intensiva e, particularmente, em rios de regiões áridas, onde a água é escassa e a evaporação alta, havendo tendência de acúmulo de sólidos (Hermes \& Silva, 2004). O limite máximo estabelecido para STD pelo CONAMA (2005) é de $500 \mathrm{mg} / \mathrm{L}$ e os açudes A e B apresentaram 7,00 $\mathrm{mg} / \mathrm{L}$ e $249 \mathrm{mg} / \mathrm{L}$ de STD, respectivamente. Portanto, em relação a esse parâmetro, a água dos dois açudes encontra-se dentro dos padrões exigidos para consumo animal.

Considerando-se os resultados obtidos e apresentados neste trabalho, é possível afirmar que as águas dos dois açudes urbanos de Sobral podem ser utilizadas para dessedentação de animais, sob a condição de que possam ser submetidas a algum tratamento simplificado, como desinfecção por radiação solar. Para as autoridades municipais da cidade de Sobral, Ceará, é recomendável a aplicação correta de medidas de controle e/ou de prevenção da contaminação dessas águas.

\section{REFERÊNCIAS BIBLIOGRÁFICAS}

AMERICAM PUBLIC HEALTH
ASSOCIATION - APHA. Standard methods
for the examination of water and
wastewater. 18. ed., A. E. Greenberg, L. S.
Clesceri, A. D. Eaton (eds.), Washington, DC:
Victor Graphics, 1992.

CONSELHO NACIONAL DO MEIO AMBIENTE - CONAMA. Resolução N o 
357, de 17 de março de 2005. DOU. N 53. Seção 1. p.58, 2005.

CONTE, V.D. Qualidade microbiológica de águas tratadas e não tratadas na região nordeste do Rio Grande do Sul. Infarma, v.16, n.11-12, p.83-84, 2004.

GARCIA, C.A.B.; BARRETO, P.R. Caracterização da qualidade da água do açude Buri-Frei Paulo/SE. Revista Scientia Plena, v.6, n.9, p.1-21, 2010.

HERMES, L.C.; SILVA, A.S. Avaliação da Qualidade das Águas: Manual Prático, p.55. Brasília, DF: Embrapa Informação Tecnológica, 2004.

KONEMAN, E.W.; ALLEN. S.D.; DOWELL, J.R.V.R.; SOMMERS, H.M. Diagnóstico Microbiológico: texto e atlas colorido. 2. ed. São Paulo: Panamericana, 1993.

LIMA, W.S.; GARCIA, C.A.B. Qualidade da Água em Ribeirópolis-SE: o Açude do Cajueiro e a Barragem do João Ferreira. Scientia Plena, v.4, n.12, 122401, 2008.

MITTELSTAEDT, S. e CARVALHO, V. M. Escherichia coli enterohemorrágica (EHEC) O157:H7. Revista do Instituto de Ciências da Saúde. v.24, n.3, p.175-182, 2006.

MOLLARET, H.H. Fifteen centuries of Yersiniosis. Contrib. Microbiol. Immunol. v.13, p.1-4, 1995.

PINTO, D.B.F.; SILVA, A.M.; MELLO, C.R.; COELHO, C. Qualidade da água do Ribeirão Lavrinha na região Alto Rio Grande - MG, Brasil. Revista Ciência e Agrotecnologia, v.33, n.4, p.1145-1152, 2009.

ITURRINO, R.P.S.; MASSOLI, V.M.C.B.; DELPHINO, T.P.C.; DAMASCENO, P.R. Clostridium perfringens em rações e águas fornecidos a frangos de corte em granjas avícolas do interior paulista - Brasil. Revista Ciência Rural, v.40 n.1, p. 197-199, 2010.
SILVA, M.C; GALLO, C.R. Avaliação da qualidade microbiológica de alimentos com a utilização de metodologia convencionais do sistema Simplate. Higiene Alimentar, v.17, n.107, p.75-85, 2003.

SILVEIRA, T. Análise físico-química da água da bacia do Rio Cabelo - João Pessoa-PB. II Congresso de Pesquisa e Inovação da Rede Norte Nordeste de Educação Tecnológica. João Pessoa - PB, 2007. Disponível em <http://www.redenet.edu.br/publicacoes/arqui vos/20080212_092019_MEIO-028.pdf>.

Acesso em: 20 de julho de 2013.

SONNE, L.; RAYMUNDO, D.L.; BOABAID, F.M.; BORBA, M.R.; SNEL, G.G.M.; GOMES, M.J.P.; DRIEMEIE, D. Infecção sistêmica por Yersinia enterocolitica em chinchilas (Chinchilla laniger). Pesquisa Veterinária Brasileira, v.32, n.5, p.379-382, 2012.

TEODORO, V.A.M.; PINTO, P.S.A.; VANETTI, M.C.D.; BEVILACQUA, P.D.; MORAES, M.P.; PINTO, M.S. Aplicação da técnica de PCR na detecção de Yersinia enterocoliticaem suínos abatidos sem inspeção. Arquivo Brasileiro de Medicina Veterinária e Zootecnia, v.58, n.1, p.9-14, 2006.

TOPP, E. Strain-dependent variability in growth and survival of Escherichia coli in agricultural soil. Microbiology Ecology, v. 44, p.303-308, 2003.

ZULPO, D.L.; PERETTI, J.; ONO, L.M.; GARCIA, J.L. Avaliação microbiológica da água consumida nos bebedouros da Universidade Estadual do Centro-Oeste, Guarapuava, Paraná, Brasil. Ciências Agrárias, v. 27, n.1, p.107-110, 2006. 